\title{
PENINGKATAN MINAT DIGITAL MARKETING BAGI SISWA SMK TEKNOLOGI KARAWANG MELALUI PELATIHAN ADOBE PHOTOSHOP
}

\author{
Lila Setiyani ${ }^{1}$, Femmy Effendy ${ }^{2}$, Jajang ${ }^{3}$, R. Mega Yulianto ${ }^{4}$ \\ 1,2Program Studi Sistem Informasi, STMIK ROSMA \\ ${ }^{3,4}$ Program Studi Teknik Informatika, STMIK ROSMA
}

\begin{abstract}
Email : ${ }^{1}$ lila.setiyani@dosen.rosma.ac.id, 2femmy@rosma.ac.id, 3jajang@dosen.rosma.ac.id, ${ }^{4}$ mega.yuliyanto@dosen.rosma.ac.id
\end{abstract}

Diterima : 08-06-2021, Di publikasikan : 16-06-2021

\begin{abstract}
Abstrak
Edukasi tentang digital marketing pada tingkat Sekolah Menengah Kejuruan(SMK) sangat penting. Mengingat, SMK difokuskan untuk siap kerja dan berwirausaha. Dengan memberikan edukasi digital marketing akan meningkatkan pemahaman serta kompetensi, sehingga siswa dapat siap terjun di masyarakat. Dalam konsep digital marketing didukung dengan pemahaman tentang konsep desain, yang merupakan tools untuk marketing. Adobe Photoshop merupakan salah satu aplikasi yang dapat digunakan untuk mendesain tools marketing yang berguna untuk implementasi digital marketing. Pada kegiatan ini, mitra SMK yang diundang untuk mengikuti pelatihan Adobe Photoshop adalah SMK TEKNOLOGI KARAWANG. Tujuan kegiatan ini adalah untuk memberikan bekal siswa dalam implementasi digital marketing melalui pelatihan desain menggunakan adobe photoshop. Prosedur yang dilakukan pada kegiatan ini dimulai dengan pre-test, koordinasi dengan mitra, persiapan materi, pelaksanaan kegiatan dan evaluasi kegiatan(post-test). Kegiatan diikuti oleh 60 peserta yang berasala dari kelas XII. Hasil kegiatan ini dapat dinyatakan sukses, hal ini dapat diperlihatkan dari tingkat pemahaman dan produk desain yang dihasilkan. Implikasi dari kegiatan ini adalah peningkatan pemahaman siswa tentang digital marketing dan penggunakan adobe photoshop sebagai aplikasi untuk medesain poster, flyer, dan lain - lain.
\end{abstract}

Kata Kunci : Adobe Photoshop, Digital Marketing, Desain, Sekolah Manengah Kejuruan.

Abstract

Education about digital marketing at the Vocational High School (SMK) level is very important. Given, SMK is focused on being ready to work and entrepreneurship. By providing digital marketing education, it will increase understanding and competence, so that students can be ready to enter the community. The digital marketing concept is supported by an understanding of the design concept, which is a tool for marketing. Adobe Photoshop is an application that can be used to design marketing tools that are useful for implementing digital marketing. In this activity, the SMK partner who was invited to take part in the Adobe Photoshop training was SMK TEKNOLOGI KARAWANG. The purpose of this activity is to provide students with supplies in the implementation of digital marketing through design training using adobe photoshop. The procedure carried out in this activity begins with a pre-test, coordination with partners, preparation of materials, implementation of activities and evaluation of activities (post-test). The activity was attended by 60 participants from class XII. The results of this activity can be declared successful, this can be shown from the level of understanding and the resulting design product. The implication of this activity is to increase students' 
Abdimas : Sistem dan Teknologi Informasi

Vol. 01, No. 01, Juni 2021: 23-29

understanding of digital marketing and the use of Adobe Photoshop as an application to design posters, flyers, and others.

Keyword : Adobe Photoshop, Digital Marketing, Design, Vocational High School

\section{PENDAHULUAN}

Penuruan sumber daya manusia level operator oleh industri manufaktur, yang merupakan salah satu penyerap lulusan Sekolah Menengah Kejuruan(SMK) merupakan permasalahan yang perlu segera di solusikan. Industri 4.0 mendorong bermunculannya industri - industri berbasis internet of thing yang diadopsi oleh industri manufaktur, hal ini berdampak pada penyerapan sumber daya manusia(Ricardianto, Nasution, Naiborhu, \& Triantoro, 2020). ECommerce dengan digital marketing, hadir memberikan kesempatan para lulusan SMK untuk dapat menciptakan usaha yang membuka peluang penyerapan sumber daya manusia. Digital marketing mendukung bisnis dengan menghemat biaya promosi dan mempermudah menjaring pasar. Teknis digital marketing dilakukan dengan memposting produk di internet baik itu melalui social commerce(Supriyati, 2015) maupun e-commerce(Handayani, 2018). Untuk dapat mendapatkan perhatian pasar, pengusaha perlu mendesain produk atau layanan mereka ke dalam bentuk media promosi. Untuk mendapatkan desain yang baik, diperlukan komptensi dalam menggunakan aplikasi - aplikasi designer. Adobe photoshop(Dewi, 2012) sebagi salah satu aplikasi yang dapat digunakan dengan mudah dalam mendesain media promosu. Mitra pada kegiatan ini adalah SMK TEKNOLOGI KARAWANG yang terus berupaya meningkatkan lulusannya agar dapat terserap di masyarakat (pekerja \& wirausaha). Pada SMK TEKNOLOGI KARAWANG belum banyak kegiatan yang berhubungan dengan digital marketing atau adobe photoshop, sehinga kegiatan ini dapat menjadi inisiasi bagi sekolah untuk dapat mengembangkan pembelajarannya ke arah desain yang dapat meningkatkan minat siswanya dalam berwirausaha melalui digital marketing.

Pelatihan dan pendampingan dalam desain media promosi, terbukti dapat meningkatkan minat berwirausaha melalui digital marketing hal ini diungkap oleh (Sahara, Indah, Heisa, Mulyani, \& P, 2020), (Ardian \& Soepeno, 2018), (Ardiyatna \& Belakang, 2019),(Martono, Al Husain, \& Iswara, 2018), (Ramadhan, 2018), (Haidar Rozsidhy \& Dwi Pribadi, 2018).

\section{METODE}

Prosedur yang dilakukan pada kegiatan pelatihan Adobe Photoshop bagi siswa SMK TEKNOLOGI KARAWANG dimulai dengan kegiatan pre-test yang dilakukan untuk mengetahui pemahaman siswa tentang Adobe Photoshop, dilanjut dengan koordinasi dengan mitra 
mengenai jadwal pelatihan. Setelah jadwal ditetapkan, dilakukan persiapan materi. Materi disusun dengan mempertimbangkan keefektivan penelitian, oleh sebab itu, materi lebih banyak menyajikan trik - trik cepat dalam mendesain media promosi. Selanjutnya pelaksanaan kegiatan dan evaluasi kegiatan melalui post-test. Pemateri dalam pelatihan ini adalah dosen dari program studi yang ada di STMIK ROSMA.

\section{HASIL DAN PEMBAHASAN}

Kegiatan dilaksanakan pada tanggal 12 sampai dengan 16 Oktober 2020 dengan peserta siswa kelas XII SMK TEKNOLOGI KARAWANG. Dalam kegiatan ini, peserta yang hadir sebanyak 60 siswa dan dihadiri oleh dua guru pendamping. Acara dimulai pukul 09.00 WIB sampai 11.00 WIB, kegitan tidak dapat dilakukan dengan waktu yang panjang mengingat keadaan pentingnya protokol kesehatan yang tidak menyarankan siswa dalam kelas dengan waktu yang lam. Pada hari pertama, peserta diberikan materi tentang peluang usaha melalui digital marketing. Materi diberikan dengan menggunakan power point yang menarik, dan mencontohkan digital marketing secara langsung, dengan sosial media yaitu Instagram dan Facebook. Siswa terlihat antusias dengan pertanyaan - pertanyaan yang menyangkut cara cara meningkatkan followers, peluang produk yang di jual, dan sebagainya. Pemateri pada hari pertama ini adalah Dosen Program Studi Sistem Informasi. Materi selanjutnya, adalah mengenai transaksi melalui media digital, ini diberikan untuk memberikan pemahaman mengenai risiko - risiko yang mungkin dapat terjadi, materi ini disajikan oleh Dosen dari Program Studi Teknik Informatika. Dalam pembahasannya, pemateri menyadikan terkait dompet digital, serta strategi - strategi untuk keamanan bertransaksi.

Pada hari kedua, materi disajikan untuk memberikan wawasan terkait, pajak yang melekat pada transaksi. Materi ini disajikan oleh dosen dari Program Studi Komputerisasi Akuntansi, yang memberikan wawasan tetang bagaimana teknis pungutan pajak PPN, PPH pasal 23, PPH badan, dan cara pelaporannya. Pemaparan materi tentang pajak ini, memberikan pamahaman bahwa, transaksi berbasis digital pun wajib melakukan pelaporan pajak. 


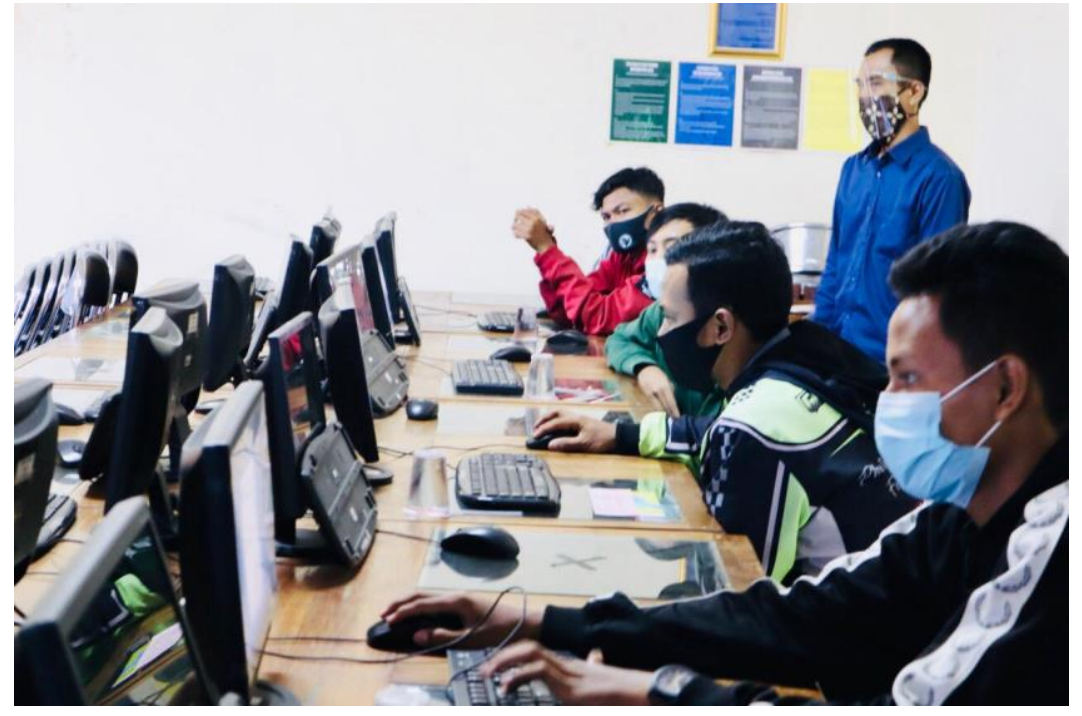

Gambar 1. Foto Kegiatan 1

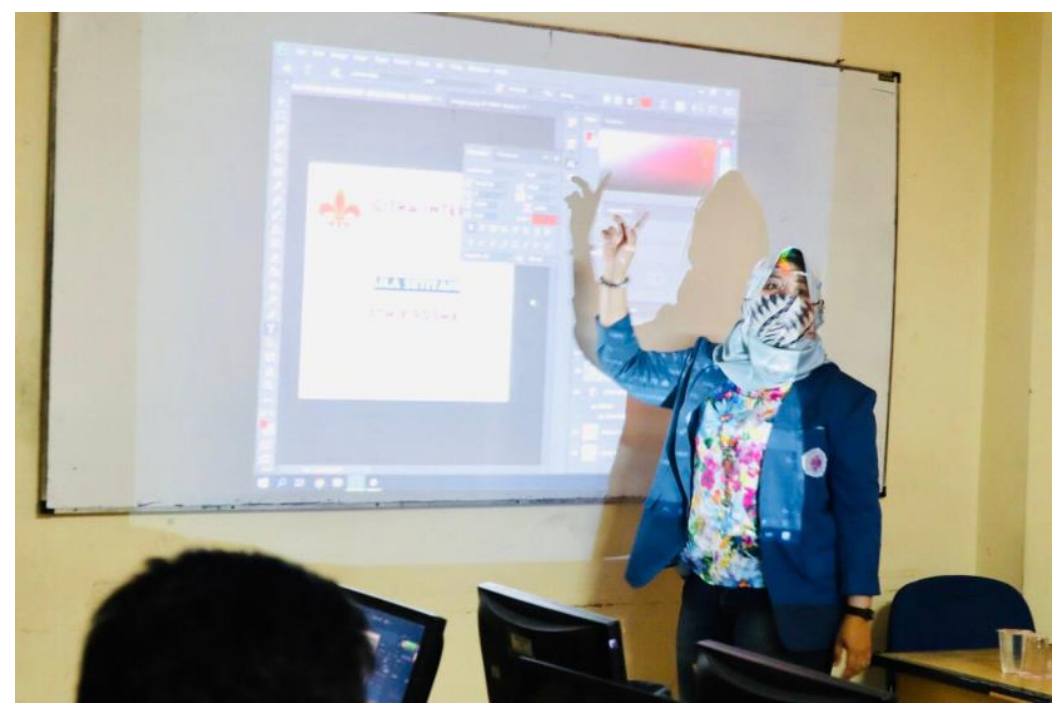

Gambar 2. Foto Kegiatan 2

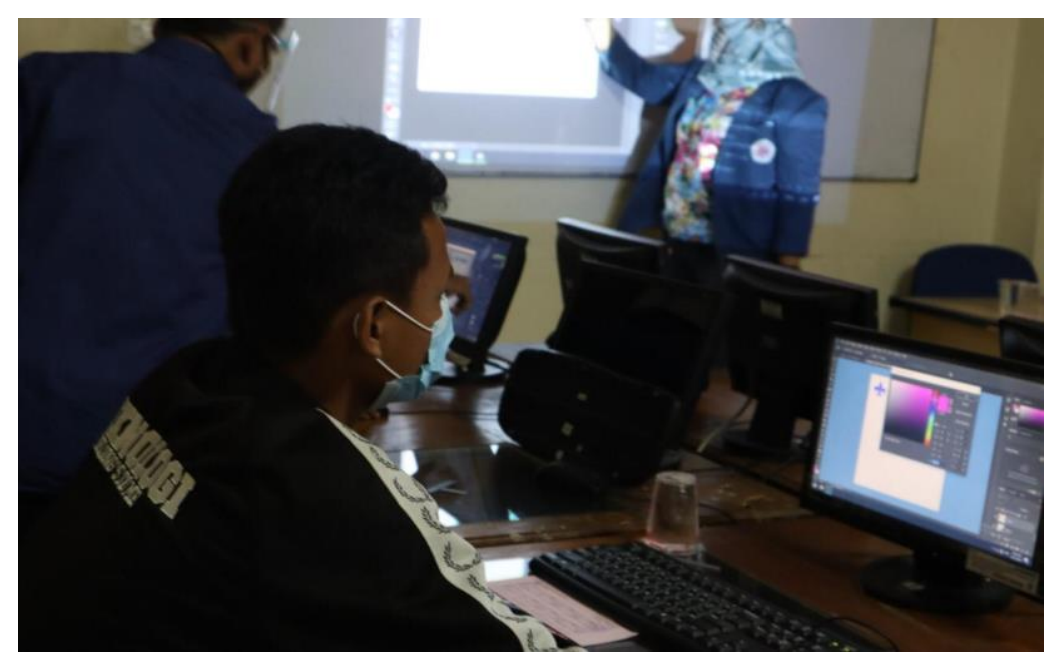

Gambar 3. Foto kegiatan 3 
Pada hari ke tiga dan ke empat, siswa melakukan praktek di laboratorium komputer yang ada di STMIK ROSMA. Siswa diberikan pemahaman tentang tools box pada aplikasi adobe photoshop. Dari tingkat dasar, siswa di berikan contoh dalam membuat media promosi sederhana. Siswa diberikan pemahaman tentang fungsi layer, kemudian penggunaan warna - warna yang tepat dan menarik. Materi ini disajikan oleh dosen Program Studi Sistem Informasi, Teknik Informatika, Manajemen Informatika dan Komputerisasi Akuntansi. Peserta di bagi empat kelas. Hari ke empat, siswa di berikan materi, membuat media promosi melalui template. Template ini dipilih agar proses desain lebih cepat. Siswa diajarkan untuk memilih template free atau gratis di link https://www.freepik.com/ . Kemudian template yang telah di download dimodifikasi sesuai dengan konsep produk yang direncanakan di jual. Pada hari ke empat ini, siswa terlihat menikmati dan mulai mengeksplore template yang diminati, yang kemudian dimodifikasi sesuai dengan keinginannya. Seluruh peserta, berhasil mengaplikasikan desain yang mereka inginkan. Dengan mengimplementasikan langsung, peserta di dorong untuk mengeksplore, sehingga membangkitkan rasa ingin tau. Hasil desain media promosi kemudian di posting pada akun Instagram dan Facebook masing - masing peserta.

Pada hari kelima, peserta disajikan evaluasi dan diminta menuliskan pengalamannya dalam mendesain media promosi. Dari hasil evaluasi, memperlihatkan bahwa seluruh peserta telah memahami, konsep digital marketing, desain media promosi dan penggunaan toolbox pada aplikasi Adobe Photoshop, serta fungsi template yang dimanfaatkan untuk mempercepat proses desain.

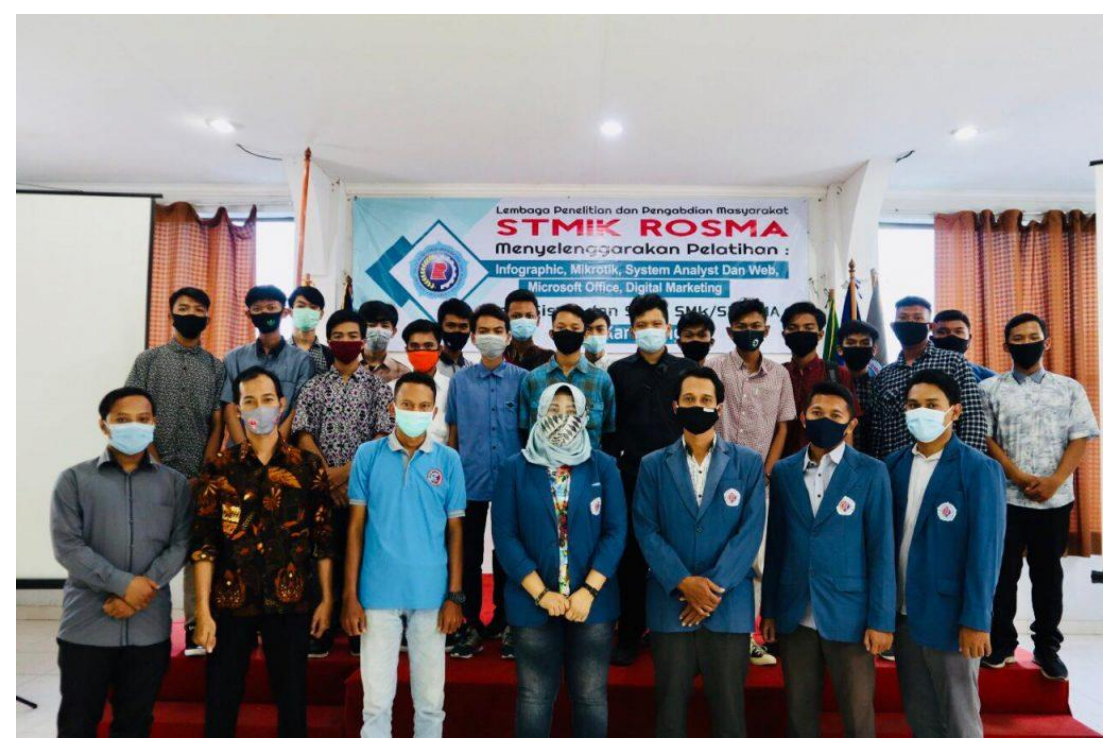

Gambar 4. Peserta dan dosen pemateri 


\section{KESIMPULAN DAN SARAN}

Kegiatan pelatihan Adobe Photoshop dalam rangka meningkatkan minat digital marketing bagi siswa SMK TEKNOLOGI KARAWANG dapat berjalan lancar, dan peserta antusias serta interaktif. Kegiatan ini dapat dinilai berhasil dengan melihat hasil implementasi produk media promosi yang telah di posting oleh peserta pada akun sosial media mereka. Melalui kegiatan ini, terjadi peningkatan pemahaman tentang digital marketing, pemahaman penggunaan aplikasi Adobe Photoshop serta penggunaan template . Untuk keberlanjutan kegiatan, dapat dilakukan pembimbingan kewirausahaan, yang terkait ide bisnis, seperti Model Bisnis Kanvas, yang akan mendorong antusias siswa SMK dalam menciptakan ide bisnis untuk berwirausaha.

\section{UCAPAN TERIMA KASIH}

Ucapan terima kasih disampaikan kepada UPT TIK STMIK ROSMA yang telah memberikan ruang kepada kami, serta Kepala Sekolah, Guru dan Siswa SMK TEKNOLOGI KARAWANG yang telah berperan dalam kegiatan ini.

\section{REFFERENCE}

Ardian, Y. D., \& Soepeno, B. (2018). Desain Katalog Produk Menggunakan Adobe Photoshop Cs6 Sebagai Media Promosi Untuk Meningkatkan Keputusan Pembelian Di Cv Bagus Agriseta Mandiri. J A B Jurnal Aplikasi Bisnis, 4(2), 407-410.

Ardiyatna, R., \& Belakang, L. (2019). DESAIN e-CATALOG MENGGUNAKAN APLIKASI ADOBE PHOTOSHOP CS3 SEBAGAI PENGEMBANGAN PROMOSI DI INSTAGRAM UNTUK MENINGKATKAN MINAT BELI PADA THREE BROTHER BLITAR. $J$ A $B$ Jurnal Aplikasi Bisnis, 5(2), 549-552. Retrieved from http://jab.polinema.ac.id/index.php/jab/article/view/386

Dewi, M. S. (2012). PENGGUNAAN APLIKASI ADOBE PHOTOSHOP DALAM MENINGKATKAN KETERAMPILAN EDITING FOTO BAGI ANAK TUNARUNGU. E-JUPEKhu, 1(2), S88-S91. https://doi.org/10.1002/ana.410230723

Haidar Rozsidhy, D., \& Dwi Pribadi, J. (2018). Pembuatan E-Katalog Produk Di Facebook Sebagai Sarana Promosi Untuk Meningkatkan Penjualan Dengan Menggunakan Aplikasi Paint Tool Sai Dan Adobe Photoshop Di Resto Ayam Bacem Bakar Gribig Malang. J A B Jurnal Aplikasi Bisnis, 4 Nomor:2,(1), 2-5.

Handayani, S. (2018). Perancangan Sistem Informasi Penjualan Berbasis E-Commerce Studi Kasus Toko Kun Jakarta. ILKOM Jurnal IImiah, 10(2), 182-189. https://doi.org/10.33096/ilkom.v10i2.310.182-189

Martono, D., Al Husain, A. H., \& Iswara, D. (2018). Media Company Profile Berbentuk Desain Booklet Menggunakan Aplikasi Photoshop Cs5 Di Pt. Citra Surya Selaras Berbasis Multimedia. SENSI Journal, 4(2), 180-190. https://doi.org/10.33050/sensi.v4i2.644

Ramadhan, K. R. (2018). Flyer Sebagai Media Promosi Pada Usaha Pencucian. JAB Jurnal Aplikasi Bisnis, 351-355.

Ricardianto, P., Nasution, S., Naiborhu, M. A., \& Triantoro, W. (2020). Peluang dan Tantangan Sumber Daya Manusia dalam Penyelenggaraan Pelabuhan Cerdas (Smart Port) Nasional 
Abdimas : Sistem dan Teknologi Informasi

Vol. 01, No. 01, Juni 2021: 23-29

di Masa Revolusi Industri 4.0. Warta Penelitian Perhubungan, 32(1), 59-66. https://doi.org/10.25104/warlit.v32i1.1524

Sahara, M., Indah, N., Heisa, P., Mulyani, S., \& P, D. G. (2020). Pendampingan Ikm Dapur Za By di Kecamatan Parung Kabupaten Bogor Jawa Barat. Seminar Nasional Pengabdian Masyarakat LPPM UMJ.

Supriyati, E. (2015). Finance, Empire and the British World. Jurnal SIMETRIS, 6(1), 1-10. https://doi.org/10.1080/03086534.2013.762151 